\title{
Experimental Study of Features of Thin-Walled Pipes Sizing in the Line of a Pipe Rolling Plant with an Automatic Mill
}

\author{
S.Yu. Belyaev ${ }^{1}$, A.A. Fedulov ${ }^{1, *}$, Yu.M. Chernyshev ${ }^{2}$, V.I. Kuznetsov ${ }^{1}$ and M.Yu. Bulganina ${ }^{1}$ \\ ${ }^{1}$ Ural Federal University, 62000219 Mira street, Yekaterinburg, Russia \\ ${ }^{2}$ Pervouralsk New Pipe Plant, 1 Torgovoya street, 623112, Pervouralsk, Sverdlovsk Oblast, Russia
}

\begin{abstract}
The aim of the study is to establish the actual level of working loads on the roll drive line of the sizing mill installed as part of the PRP220 with an automatic mill, when switching to the production of steel pipes from increased strength group. The study is based on a complex experimental and theoretical analysis. After the processing of the results of experimental studies a comparison of the most loaded sizing route for a thin-walled pipe with a diameter of $244.5 \mathrm{~mm}$ and a wall thickness of 8.9 $\mathrm{mm}(\mathrm{D} / \mathrm{S}=27.5)$ made of steel of strength group " $\mathrm{D}$ " was made with the route for a pipe with a diameter of $177.8 \mathrm{~mm}$ and a wall thickness of 9.2 $\mathrm{mm}(\mathrm{D} / \mathrm{S}=19.3)$ from steel of strength group " $E$ ". Graphs of the observed processes are presented, as well as calculated predictive values of sizing of thin-walled pipes for steel of strength group "E", obtained on the basis of an experimental-theoretical analysis of the growth of flow stress. Recommendations have been given for improving the equipment of the PRP-220 sizing mill for the production of pipes with increased diameters from steels of increased strength groups.
\end{abstract}

\section{The problem statement}

Sizing mills as part of pipe rolling plants perform the process of calibrating the diameter of the rough pipe in several two-roll stands of lengthwise rolling, inclined relative to the horizon at an angle of $45^{\circ}$ and turning the plane of the inter-roll gap of each subsequent stand relative to the previous one at an angle of $90^{\circ}[1,2]$. It is during this operation that the pipe is given the final geometric shape in terms of diameter, as a result of which it is necessary to ensure the stability of the sizing process.

One of the most important factors that make it possible to judge the quality and stability of pipe sizing are the energy-power parameters of this process, namely the forces and moments of rolling in the stands. These parameters directly characterize, on the one hand, the loading of the working stands and their drives, and on the other hand, the technological loads determine the elastic deformation of the working stands of the rolling mills and are associated with the forming of the final geometric dimensions of the pipes.

\footnotetext{
* Corresponding author: artem.feduloff@yandex.ru
} 
The object of the study was the main lines of the working stands of a 5-stand sizing mill, which is included in the technological line of the pipe-rolling plant PRP-220 with an automatic mill of JSC "Pervouralsk New Pipe Plant" (PNTZ).

Initially, this PRP-220 was intended for the production of pipes with a diameter of up to $219 \mathrm{~mm}$, mainly from carbon and low-alloy steels. Recently, the assortment of products has undergone a change in the direction of increasing the diameters of manufactured pipes - up to $245 \mathrm{~mm}$ from alloys of strength group " $D$ ", without significant upgrade of the equipment. As a result, the frequency of equipment failures has increased due to a rise in technological loads. These failures lead to long shutdowns of the entire complex of the pipe-rolling plant, which naturally reduces the technical and economic indicators of its performance. In future, it is planned to master the production of pipes with a diameter of $245 \mathrm{~mm}$ from steels of the "E" group, but this requires scientific substantiation of the absence of overloads in the drive lines of various mills, which can be implemented within the framework of a comprehensive experimental and theoretical study.

Previously [3-5], the team of authors considered the issue of the workability of other units in the considered pipe-rolling plant 220 - automatic and reeling mills in the course of expanding the technological capabilities of this equipment. In the course of the study, it was found that as a result of constrained deformation and loss of stability in the calibres of the automatic mill, outlets - "fins" are formed at the ends of the pipe (Fig. 1), which then form folds during deformation on the reeling mill, and then pipes with these defects are transferred to the sizing mill.

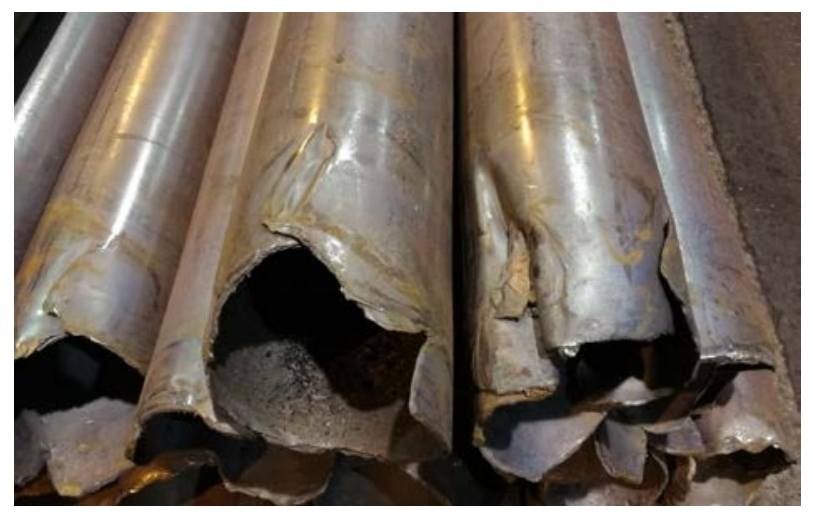

Fig. 1. Damaged ends of thin-walled pipes after finishing forming operations on the PRP 220.

For most of the traditional standard sizes of pipes produced on the PRP-220 with a "diameter-wall thickness" ratio $(\mathrm{D} / \mathrm{S})$ of no more than $15 \ldots 18$, no defects appear at the end area, and the reeling and sizing operations are stable. For thin-walled pipes, the value of defects increases with increasing of $\mathrm{D} / \mathrm{S}$ and, accordingly, with further forming of such pipes, a peak overload of the equipment occurs up to five or more compared to nominal values in the steady state. Similar processes can occur during the pipe sizing.

Based on the foregoing, the objectives of the study were:

- the experimental determination of the real level of working loads and dynamics of the drive lines of the rolls of the sizing mill, taking into account the whole variety of operating factors.

- the determination of the level of technological loads in the rolling of the most common standard sizes of pipes, as well as pipes with a diameter of up to $245 \mathrm{~mm}$ from steels of strength group "D" on a sizing mill. 
- the prediction of the level of technological loads during the rolling of pipes with a diameter of up to $245 \mathrm{~mm}$ from steels of strength group "E" on a sizing mill.

- the development of scientifically grounded recommendations for improving the technological modes of deformation and designs of the equipment of the PRP-220 sizing mill and the modes of its operation.

\section{The registration of parameters on the sizing mill in the rolling of thin-walled pipes}

The solution of above-mentioned problems, as well as the use of the developed recommendations in the practice of modelling the technological processes of rolling and the operation of equipment on the PRP-220, will reduce the reliability of long-term failures on the sizing mill and thereby increase the technical and economic efficiency of the piperolling plant as a whole unit.

As a research method, an experimental-theoretical analysis of the calibration processes was adopted, during which the real values of technological loads were determined by experimental methods, and the predicted values for high-strength steels were calculated on the basis of experimental data, taking into account the theoretical dependences of the mechanical properties of metals during hot deformation.

The schematic diagram of the drive of the sizing mill and the placement of technical means of experimental research is shown in Figure 2. The drive diagram includes: working stands (5 pieces), combined bevel-cylindrical gearboxes for drive rolls of stands (intermediate and gear drives - 5 pieces), intermediate bevel distribution gearboxes (2 pieces), main clutch, helical gearbox, motor clutch, main electric motor.

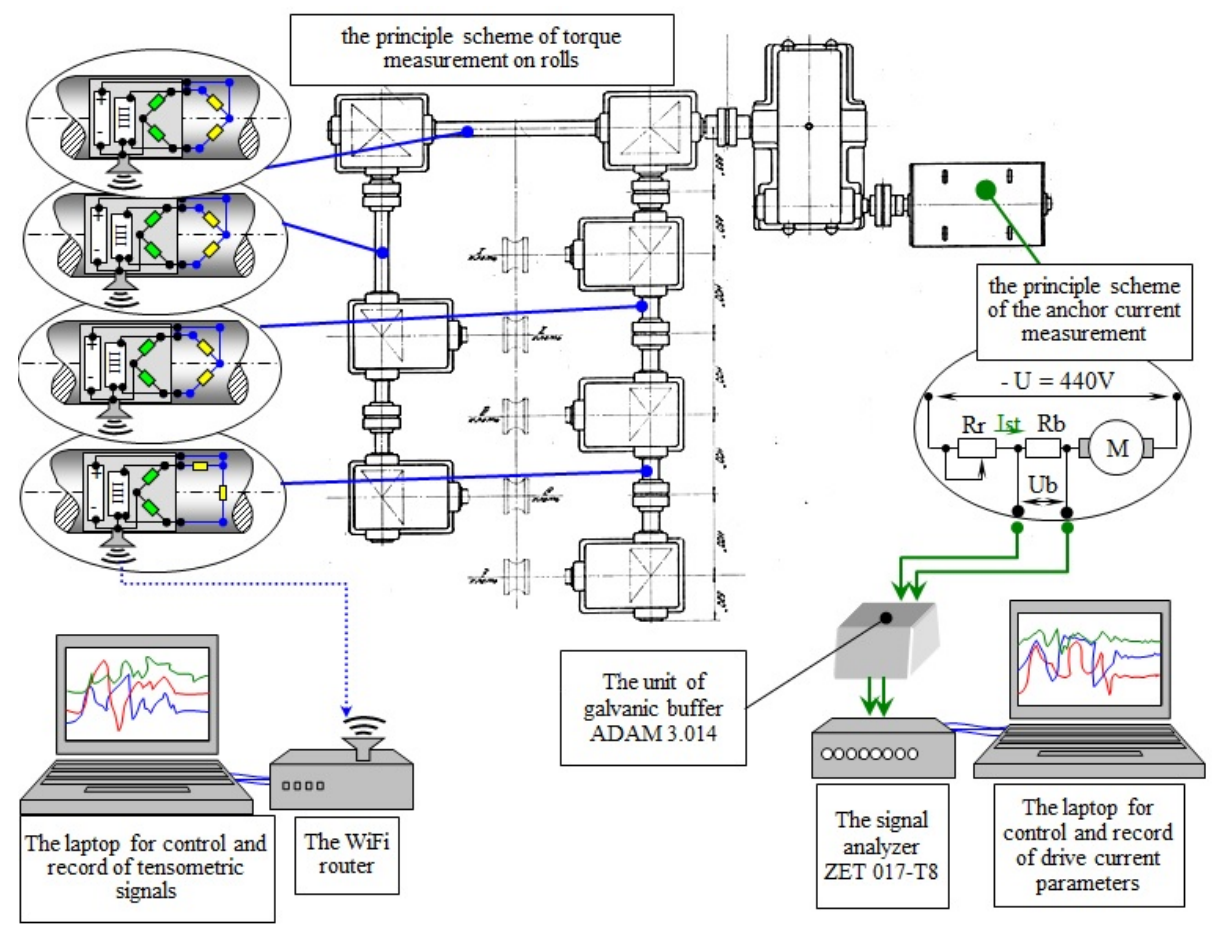

Fig. 2. The principle scheme of the sizing mill drive and the placement of the experimental research tools. 
To register the parameters, two parallel working measurement schemes were used:

- to register the current parameters of the electric drive of the working stands,

- for registration of signals from torque sensors - the wireless data transmission system (WDTS).

The frequency of rotation of the shaft of the main electric motor of the sizing mill and the current of the anchor chain were recorded using standard tools. The readings of these devices, in turn, are direct signals taken from the shunts of the anchor circuit of the electric motor. The signal was connected to the signal analyser ZET 017-T8 through the galvanic buffer unit ADAM 3.014, which provided both protection of the measuring circuit from abnormal voltages, currents and potentials, and the exclusion of an accidental counter voltage supply to the control systems of the main electric motors of the sizing mill. To assess the dynamics of the current loads of the electric motors of the drive lines on the rolls of the sizing mill, powered by direct current with a voltage of $440 \mathrm{~V}$, the polling cycle of the recorded signal was $0.02 \ldots 0.04 \mathrm{~s}$, which corresponds to a polling frequency of $25 \ldots 50 \mathrm{~Hz}$.

The measurement of the torque transmitted by the intermediate shafts was carried out by the method of electric strain gauging $[6,7]$. To record the torques on the smooth part of the shafts (Fig. 2), strain gauge socket (half-bridge circuit) of two FK-20-100 sensors, respectively, and receiving-transmitting units were placed. The tensor sockets were powered from autonomous power supplies - batteries installed in the receiving and transmitting devices. The output signals of the tensor sockets were sent to the controllers of the receiving and transmitting units and, after digitization, were transmitted via Wi-Fi wireless network to the router and then to the laptop. The calibration of strain gauges and measuring circuits was carried out according to a special method on a calibration beam of equal resistance, and the calibration results show a fairly high degree of linearity of the sensor readings. To assess the dynamics of the main line of the sizing mill, the polling cycle of the main energy-power parameters was $0.016 \mathrm{~s}$.

The steel grade, diameter, length of rolled pipes and the multiplicity of cutting of the original billet were recorded according to the accompanying documentation for each specific batch. The dimensions of the initial rough pipe, the dimensions of the roll grooves were taken in accordance with the actual setting of the rolling machines and the sizing mill, and were also compared with the rolling table.

During the inspection of the equipment of the PRP-220 sizing mill, special methods of experiment planning were not used due to the presence of a rather intense production program. In accordance with the production plan, a series of measurements of the regular technological processes for different standard sizes of pipes and steel grades were planned. The research program included a study of the routes of rolling pipes with diameters of 159 $\mathrm{mm}, 168.3 \mathrm{~mm}, 177.8 \mathrm{~mm}, 219 \mathrm{~mm}, 244.5 \mathrm{~mm}$ with various wall thicknesses from 6 to 16 $\mathrm{mm}$. The grade composition of the steels observed during the work was also quite wide carbon, alloyed and corrosion-resistant steels (20, 09G2S, 13HFA, 45, D, 37G2F, 08H18N10T in Russian standarts).

\section{Processing of experimental research results}

The arrays of digital data obtained in the course of the experimental study were processed with the aim of converting into a form convenient for further visualization of the results, taking into account the calibration coefficients for each of the parameters, as well as for presenting information in the form most convenient for reading, analysis and comparison.

The actual analysis of the research results included a qualitative analysis aimed at determining the main, fundamental features of the process of the rough pipes rolling on the PRP-220 sizing mill, and a quantitative analysis, as a result of which the main relationships 
between the real energy-power parameters of the process and the limiting levels of equipment load were obtained.

The mechanical properties of steels for the production of pipes on the PRP-220 were set taking into account the real temperature-deformation conditions, obtained on the basis of the analysis of rolling processes on the sizing mill (Table 1).

Table 1. Mechanical properties of steels of strength groups "D" and "E" in the hot state for rolling conditions on a sizing mill.

\begin{tabular}{|c|c|c|c|}
\hline \multirow{2}{*}{$\begin{array}{c}\text { The deformation } \\
\text { temperature }\end{array}$} & \multicolumn{2}{|c|}{$\begin{array}{c}\text { Flow stress (MPa) under the strain of 0.05 (5.0\%) } \\
\text { and the strain rate 5.0 s }\end{array}$} & \multirow{2}{*}{$\begin{array}{c}\text { \% of loading } \\
\text { growth }\end{array}$} \\
\cline { 2 - 3 } & $\begin{array}{c}\text { Steel grade "D" (Steel } \\
45)\end{array}$ & $\begin{array}{c}\text { Steel grade "E” (Steel } \\
\text { 37G2F) }\end{array}$ & \\
\hline 900 & 87 & 114 & 31.0 \\
\hline 850 & 100 & 133 & 33.0 \\
\hline 800 & 114 & 154 & 35.1 \\
\hline 750 & 131 & 179 & 36.6 \\
\hline 700 & 150 & 208 & 38.7 \\
\hline
\end{tabular}

Comparison of the results obtained makes it possible to calculate the predicted values of the loads for the entire series of alloys, even if experimental data are obtained for only one alloy. The data given in the Table 1 show that when the sizing of pipes made of steels of strength group "E", the flow stress increases by $1.31 \ldots 1.39$ times, in relation to the true yield strength for steels of strength group "D". Therefore, when predicting technological loads in pipes sizing made of steels of a higher strength group, the average coefficient of increase in energy-power parameters was taken to be 1.35.

Figure 3 shows the results of processing the data of an experimental study of loads in the sizing of a pipe with a diameter of $177.8 \mathrm{~mm}$ and a wall thickness of $9.2 \mathrm{~mm}$ (ratio $\mathrm{D} / \mathrm{S}=19.3$ ) from steel $37 \mathrm{G} 2 \mathrm{~F}$ (steel of strength group "E"), namely the results measuring current loads and total torque required for sizing (torque on the output shaft of the helical gearbox).

Analysis of the results shows that the sizing process is quite stable both within a batch of billets and when sizing one pipe. Exceeding the permissible values, both in currents and torques, were not recorded. Technological loads predictably increase and decrease stepwise, which corresponds to the phases of metal presence in the mill stands. When sizing the front and rear ends of the pipe, the technological loads increase, since at this moment the cooled end sections are rolled. On the ascending and descending sections of the load graph, only 4 levels of loads are clearly expressed, corresponding to the beginning or end of rolling in stands from the second to the fifth. The deformation in the first stand is the minimum required to grip the pipe with the rolls, which is correspond with the rules for choosing reductions on sizing mills.

Figure 4 shows the results of processing the data of the experimental study of loads when sizing the pipe from an extended diameter range of $244.5 \mathrm{~mm}$ with a wall thickness of $8.9 \mathrm{~mm}$ (ratio $\mathrm{D} / \mathrm{S}=27.5$ ) from steel of strength group " $\mathrm{D}$ ". Both the results of measuring the current loads and the total torque required for sizing (torque on the output shaft of the helical gearbox) are presented. 


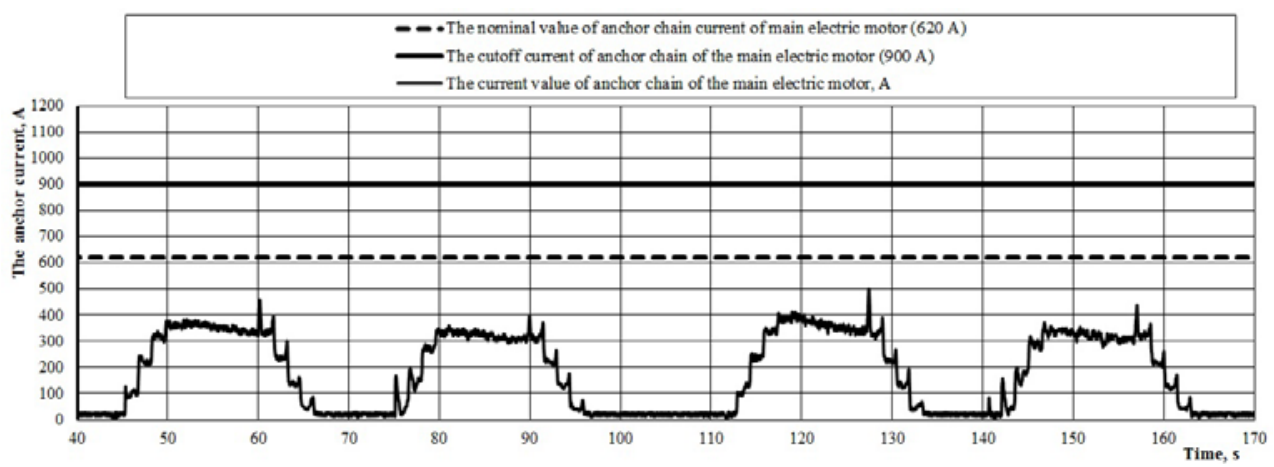

(a)

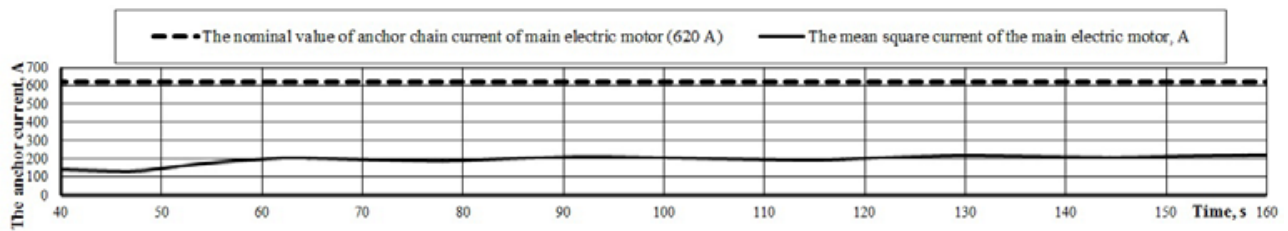

(b)

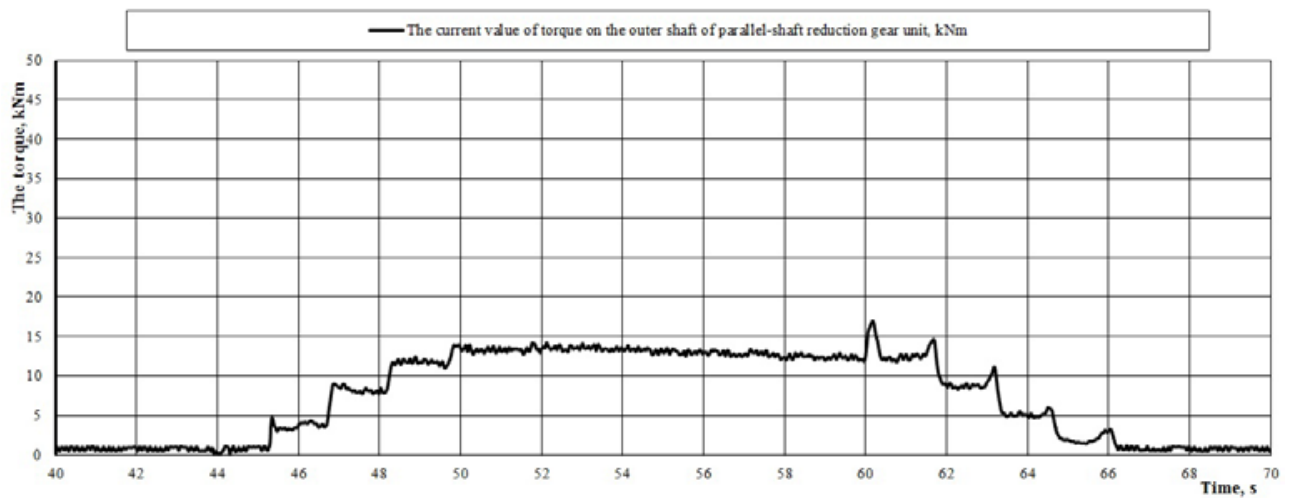

(c)

Fig. 3. Graphs of the registered sizing process parameters for a pipe with a diameter of $177.8 \mathrm{~mm}$ and a wall thickness of $9.2 \mathrm{~mm}$ from $37 \mathrm{G} 2 \mathrm{~F}$ steel of strength group "E" (a) of the electric motor currents for a batch of pipes, (b) of the mean-square currents for a batch of pipes, (c) of the torque at the output of the cylindrical gearbox (total torque for calibration) for the 1 st pipe of the batch.

The graphs show the real values of the loads and their predicted values for the calibration of similar pipes made of steels of the "E" strength group. The predictive characteristics are obtained on the basis of the above consideration of the increase in the flow stress (Table 1).

The considered pipe relates to thin-walled pipes, since $\mathrm{D} / \mathrm{S}=27.5$. As a result, in addition to the previously noted features of the sizing process, the appearance of a peak load at the end of pipe sizing in the most loaded second stand is added. This is due to the previously considered effect of the formation of "fins" during the rolling on an automatic mill and their subsequent passage in the reeling machines with the formation of folds of double or triple thickness. The penetration of these defects into the rolls of the sizing mill just leads to the occurrence of this peak load. 


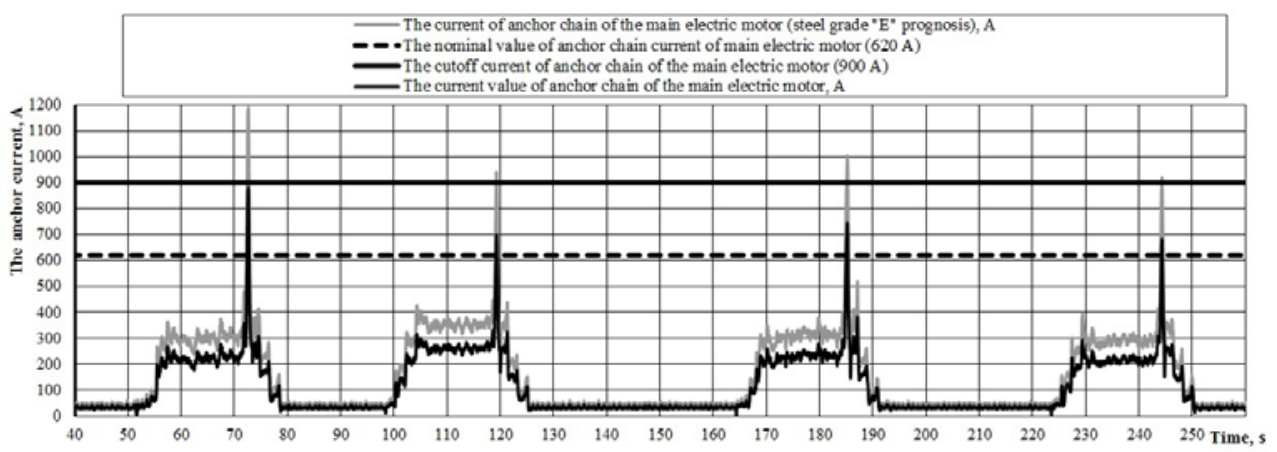

(a)

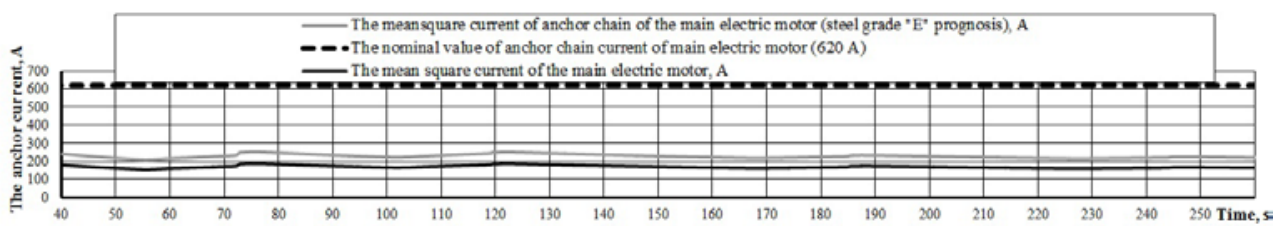

(b)

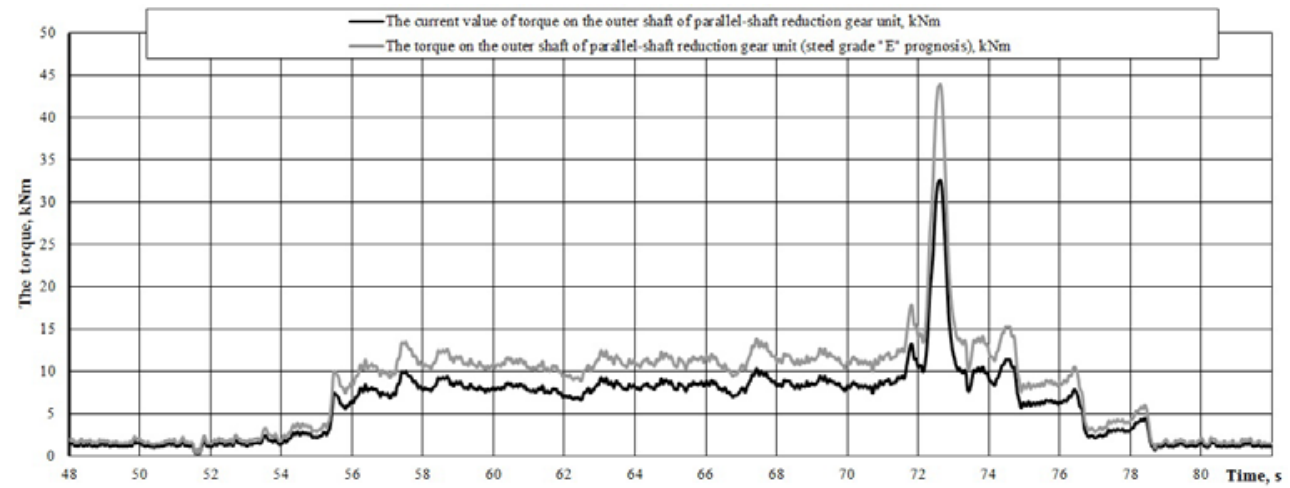

(c)

Fig. 4. Graphs of the registered (black) sizing process parameters for a pipe with a diameter of 244.5 $\mathrm{mm}$ and a wall thickness of $8.9 \mathrm{~mm}$ made of steel of strength group "D" and predictive (grey) parameters of the sizing process for a similar pipe made of steel of strength group " $E$ " (a) of the electric motor currents for a batch of pipes, (b) of the mean-square currents for a batch of pipes, (c) of the torque at the output of the cylindrical gearbox (total torque for calibration) for the 1st pipe of the batch.

The amplitude of the peak load when sizing a given pipe is $200 \ldots . .300 \%$ higher than the steady-state level of currents and torques during the rolling of the middle part of the pipe. At the same time, the amplitude of the peak load is a variable value, since the formation of the "fin" - "fold" defect depends on the setting factors of the automatic and reeling mills, as well as on the position of the fold relative to the sizing mill roll grooves.

When sizing thin-walled pipes of an extended diameter range made of steels of strength group "D", the permissible values for currents and torques were not exceeded, although the maximum peak current load of the main electric motor reaches $98 \%$ of the cut-off current. When sizing thin-walled pipes of an extended range made of steels of strength group "E", the current of the armature winding of the main electric motor will exceed the cut-off level by $10 \ldots 25 \%(900 \mathrm{~A})$ when rolling the rear end of the pipe with one or several folds. In 
steady state, the load levels will be $300 \ldots 350 \mathrm{~A}$, which is $50 \ldots 58 \%$ of the nominal value $(620 \mathrm{~A})$. Taking into account the short duration of the overload due to the rolling of the rear end of the pipe with folds and the long acting current of a low level during the steady running process, as well as significant pauses, it can be concluded that there will be no overheating of the main electric motor. Its meansquare torque load will increase from $27 \%$ to $34 \%$ of the rated current. Separately, it is necessary to consider the possibility of increasing the cut-off current to the level of $1200 \mathrm{~A}$, which corresponds to the permissible two-fold overload factor of the electric motor.

From the point of view of the strength of mechanical equipment, it should be noted that the registration of loads showed their uneven distribution between the working stands and between the drive shafts of the even and odd working stands. At the same time, the performed calculations of gear drives for endurance in contact stresses and fatigue in bending stresses at steady-state and peak loads and established load irregularities show the possibility of calibrated pipes of an extended diameter range from steels of strength group "E".

This article was prepared with the financial support of Competitiveness Enhancement Program - CEP 3.1.1.1-20.

\section{References}

1. V.Ya. Osadchy, A.S. Vavilin, V.G. Zimovets, A.P. Kolikov, Technologies and equipment for pipe production (Intermet Engineering, Moscow, 2001)

2. V.N. Danchenko, A.P. Kolikov, B.A. Romantsev, S.V. Samusev, The technology of pipe production (Intermet Engineering, Moscow, 2002)

3. Yu.B. Chechulin, S.Yu. Belyaev, V.I. Kuznetsov, V.A. Morgunov, V.Yu. Vert, Steel Transl, 49 (6), 408 (2019)

4. Yu.B. Chechulin, A.A. Fedulov, M.Yu. Bulganina, A.I. Dronov, V.A. Morgunov, IOP Conf. Ser.: Mater. Sci. Eng. 718012004 (2020)

5. S.Yu. Belyaev, Yu.B. Chechulin, A.A. Fedulov, M.Yu. Bulganina, IOP Conf. Ser.: Mater. Sci. Eng. 718012002 (2020)

6. E.Yu. Raskatov, V.A. Spiridonov, The fundamentals of scientific research and modelling of metallurgical machines (UrFU, Yekaterinburg, 2015)

7. V.A. Meheda, The strain gauge method of deformation measurement (SSAU, Samara, 2011) 